Article

\title{
Functional Properties and Sustainability Improvement of Sourdough Bread by Lactic Acid Bacteria
}

\author{
Vera Fraberger *(D), Claudia Ammer and Konrad J. Domig \\ Department of Food Science and Technology, BOKU-University of Natural Resources and Life Sciences Vienna, \\ Muthgasse 18, 1190 Vienna, Austria; claudia.ammer@gmx.at (C.A.); konrad.domig@boku.ac.at (K.J.D.) \\ * Correspondence: vera.fraberger@boku.ac.at; Tel.: +43-1-47654-75464
}

Received: 6 November 2020; Accepted: 28 November 2020; Published: 30 November 2020

\begin{abstract}
Preventing food spoilage without the addition of chemical food additives, while increasing functional properties of wheat-based bakery products, is an increasing demand by the consumers and a challenge for the food industry. Within this study, lactic acid bacteria (LAB) isolated from sourdough were screened in vitro for the ability to utilize the typical wheat carbohydrates, for their antimicrobial and functional properties. The dual culture overlay assay revealed varying levels of inhibition against the examined fungi, with Lactiplantibacillus plantarum S4.2 and Lentilactobacillus parabuchneri S2.9 exhibiting the highest suppression against the indicator strains Fusarium graminearum MUCL43764, Aspergillus fumigatus, A. flavus MUCL11945, A. brasiliensis DSM1988, and Penicillium roqueforti DSM1079. Furthermore, the antifungal activity was shown to be attributed mainly to the activity of acids produced by LAB. The antibacillus activity was evaluated by the spot-on-the-lawn method revealing a high inhibition potential of the majority of $\mathrm{LAB}$ isolated from sourdough against Bacillus cereus DSM31, B. licheniformis DSM13, B. subtilis LMG7135, and B. subtilis S15.20. Furthermore, evaluating the presence of the glutamate decarboxylase gen in LAB isolates by means of PCR showed a strain dependency of a potential GABA production. Finally, due to improved functional activities, LAB isolated from sourdoughs exhibit promising characteristics for the application as natural preservatives in wheat-based bakery products.
\end{abstract}

Keywords: sourdough; lactic acid bacteria; spoilage; molds; bacilli; $\gamma$-aminobutyric acid

\section{Introduction}

Within the last years, the importance of the new term "clean label" has increased due to a rising awareness of the consumer regarding healthiness and sustainability of food products [1]. Hence, the industry is investigating the potential application of natural alternatives to chemical food additives. Fermentation processing is one of the oldest technologies applied and is an effective way for bio-preservation, leading to improved sensory and nutritional qualities, and an increased microbiological safety and shelf life [2]. These reasons led to a regained momentum of sourdough products within the last years [3]. Lactic acid bacteria (LAB) dominate the sourdough microbiota and co-exist with yeasts, being present generally at a ratio of LAB to yeasts of 100:1 [4], in which the metabolism of LAB is especially considered to primarily determine the numerous functional advantages of sourdough [5].

The preservative effect obtained by the application of sourdough is mainly due to the production of lactic and acetic acids, which leads to a drop of the $\mathrm{pH}$, with a stable sourdough exhibiting $\mathrm{pH}$ values of approximately 3.5 to 4.0 [6]. Furthermore, antimicrobial compounds, such as bacteriocins, ethanol, hydrogen peroxide, and fatty acids are secreted by several lactobacilli to inhibit the growth of undesired 
microorganisms [7]. Mold [8] and rope spoilage [9] are key limiting factors for the shelf life of bread resulting in pecuniary losses for the baking industry $[10,11]$. Therefore, several studies have focused on the biological control of these foodborne pathogens, showing proper antifungal and even anti-aflatoxigenic [12-14], as well as antibacterial potential of sourdough LAB [15]. The contaminants mainly derive from the baking environment, flour, yeast, or further ingredients $[9,16]$ and exhibit suitable growth conditions within the bread regarding the water activity $\left(\mathrm{a}_{\mathrm{w}}\right)$ and $\mathrm{pH}$ [17].

In the case of rope spoilage, Bacillus species, such as B. subtilis, B. cereus, B. licheniformis, and $B$. pseudomesenteroides are assumed to be the main triggers $[9,11,17,18]$. Bacillus spores are heat resistant and survive the baking temperatures within the crumb ranging from $97-101^{\circ} \mathrm{C}$ for a few minutes. The endospores germinate under the favorable conditions within the bread $\left(\mathrm{a}_{\mathrm{w}}>0.95, \mathrm{pH}>5\right)$ and lead to its deterioration [18]. This process starts with an unpleasant odor similar to cantaloupe [10]. Further, microbial amylases and proteases lead to the breakdown of starch and proteins, resulting in a discolored, sticky crumb, and slimy extracellular polysaccharides, in which these visible ropes appear within 12-24 h after baking [17].

The most common molds associated with bread spoilage belong to the genera Aspergillus, Penicillium [19], Fusarium, Rhizopus, and Mucor [20]. Due to the ubiquitous occurrence of the conidiospores in the biosphere and the favorable growth conditions within the bread, fungal growth is supported [8]. Several fungi are known for their potential to produce mycotoxins, which are toxic secondary metabolites, exhibiting acute or chronic toxicity, for example, cancerogenic or nephrotoxic activity [21].

In addition to the antimicrobial effect, LAB have been associated with the production of bioactive compounds, which exhibit an advantageous impact on the nutritional quality and sensory aspect of bakery products. In this context, GABA ( $\gamma$-aminobutyric acid) is of interest. This non-protein amino acid is synthesized by the enzyme glutamate decarboxylase (GAD), which catalyzes the decarboxylation of L-glutamate to GABA [22]. The GAD system contributes to an increased bacterial acid resistance [23]. Furthermore, the presence of this amino acid is related to beneficial health effects, such as a hypotensive effect, antidiabetic, and neurotransmission, as well as depression and anxiety reduction properties due to tranquilizer effects [24-26]. Fermented foods have been proven to be an excellent source of GABA, in which $\mathrm{LAB}$ exerting the GAD system are contributing to the high concentrations in sourdough of up to $39 \mathrm{mg} / \mathrm{kg}$ [27].

The advantageous effects exerted by LAB on human wellbeing are known for a long time and are industrially used due to their potential to increase the safety, sensory, and stability of foods $[28,29]$. Furthermore, LAB have been applied for decades in food preservation, leading to their classification as generally recognized as safe (GRAS) and some of the species are harboring the qualified presumption of safety (QPS) status [30].

Therefore, this study aimed to screen LAB isolated from traditional Austrian type I wheat and rye and type III sourdoughs concerning their antimicrobial activities and the presence/absence of the GAD gene for further industrial applications on wheat-based bakery products.

\section{Materials and Methods}

\subsection{Matrices, Producer, and Indicator Strains}

LAB isolates used within this study were previously obtained from traditional Austrian wheat and rye sourdoughs as previously published by Fraberger, et al. [31] or reactivated dried wheat sourdoughs. Prior to the measurements, cryoprotected isolates $\left(-80^{\circ} \mathrm{C}\right)$ were revitalized in MRS broth (Merck, Darmstadt, Germany) overnight at $30^{\circ} \mathrm{C}$ under anaerobic conditions.

In total, $184 \mathrm{LAB}$ isolates (producers) were screened for their ability to utilize the typical wheat carbohydrates (fructose, maltose, glucose, raffinose, sucrose, and maltodextrin) and the presence/absence of the GAD gene. Furthermore, 77 isolates were selected to analyze the potential to inhibit the growth of five fungal species. Further, 65 isolates were chosen for the evaluation of their 
antibacillus activity against four indicators, especially against those responsible for the spoilage of bakery products.

Indicator strains were either purchased from DSMZ (Leibniz-Institute DSMZ-German Collection of Microorganisms and Cell Cultures; Braunschweig, Germany) or BCCM/MUCL (Belgian Coordinated Collection of Microorganisms/Agro-food and Environmental Fungal Collection; Bruxelles, Belgium) databases. The indicator strain Bacillus subtilis S15.20 was isolated from sourdough (Table 1).

Table 1. Information of strains used for the determination of antifungal and antibacillus activity.

\begin{tabular}{|c|c|c|}
\hline Species & Strain & Source of Isolation \\
\hline Bacillus cereus & $\mathrm{DSM}^{1} 31$ & unknown \\
\hline Bacillus licheniformis & $\mathrm{DSM}^{1} 13$ & unknown \\
\hline Bacillus subtilis & $\mathrm{DSM}^{1} 7135$ & unknown \\
\hline Bacillus subtilis & isolate S15.20 & sourdough \\
\hline Aspergillus flavus & MUCL $^{2} 11945$ & wheat flour \\
\hline Aspergillus fumigatus & n.d. ${ }^{3}$ & unknown \\
\hline Aspergillus brasiliensis & DSM $^{1} 1988$ & Vaccinium sp., fruit \\
\hline Penicillium roqueforti & DSM $^{1} 1079$ & gorgonzola cheese \\
\hline $\begin{array}{c}\text { Gibberella zeae } \\
\text { [anamorph Fusarium graminearum] }\end{array}$ & MUCL $^{2} 43764$ & wheat before malting \\
\hline
\end{tabular}

\subsection{Carbohydrate Metabolism}

LAB isolates, listed in Table S1, were characterized for their carbohydrate metabolism profile typically present in Austrian wheat [32]. The growth of isolates was tested on D-(-)-fructose (Merck, Darmstadt, Germany), D-(+)-raffinose (Diagonal GmbH \& Co. KG, Münster, Germany), D-(+)-maltose (Sigma-Aldrich, St. Louis, MO, USA), sucrose (Merck, Darmstadt, Germany), D-(+)-glucose (Carl Roth, Karlsruhe, Germany), and maltodextrin (Sigma-Aldrich, St. Louis, MO, USA) as sole carbohydrate sources. Reactivated isolates were transferred into a $5 \mathrm{~mL}$ MRS broth and incubated for $24 \mathrm{~h}$ at $30{ }^{\circ} \mathrm{C}$ under anaerobic conditions $\left(\mathrm{N}_{2} 85 \%, \mathrm{H}_{2} 5 \%, \mathrm{CO}_{2} 10 \%\right)$. Further, the MRS broth lacking carbohydrates (condalab, Madrid, Spain) was inoculated with $2 \%(v / v)$ of the corresponding culture and incubated for $48 \mathrm{~h}$ at $30{ }^{\circ} \mathrm{C}$ under anaerobic conditions. One hundred sixty microliters of the carbohydrate media (MRS broth with $2 \%(v / v)$ of the corresponding carbohydrate) were transferred into 96-well plates and inoculated with $3.2 \mu \mathrm{L}$ of bacterial suspension. Wells were overlaid with paraffin oil (biomerieux, Marcy l'Etoile, France) to generate anaerobic conditions and incubation was carried out at $30^{\circ} \mathrm{C}$.

Prior to the measurements, plates were shaken for $10 \mathrm{~min}$ at $30^{\circ} \mathrm{C}$ for $1450 \mathrm{rpm}$ using a bioShake $\mathrm{iQ}\left(\mathrm{Q}\right.$ instruments, Jena, Germany). Afterwards, the optical density at $620 \mathrm{~nm}\left(\mathrm{OD}_{620}\right)$ was examined in a plate photometer (Tecan Sunrise, Männedorf, Switzerland) for up to 7 days in duplicates.

\subsection{Determination of Antifungal Activity by the Dual Culture Overlay Assay}

The dual culture overlay assay (illustrated in Figure S1a) was performed to evaluate the antifungal activity of $77 \mathrm{LAB}$ isolates (producers) for their potential to inhibit the growth of five fungal species (indicators). LAB isolates belonged to species Levilactobacillus (Lev.) brevis, Lev. hammesii, Lev. senmaizukei, Lev. spicheri, Loigolactobacillus (Lo.) coryniformis, Latilactobacillus (La.) curvatus, Lentilactobacillus (Len.) diolivorans, Len. kisonensis, Len. otakiensis, Len. parabuchneri, Companilactobacillus (Co.) kimchii, Co. paralimentarius, Lactiplantibacillus (Lp.) plantarum, Lp. xiangfangensis, Limosilactobacillus (Li.) pontis, Furfurilactobacillus (Fu.) rossiae, Latilactobacillus (Lat.) sakei, Fructilactobacillus (Fr.) sanfranciscensis, Lacticaseibacillus (L.) paracasei, Paucilactobacillus (Pa.) vaccinostercus, Pediococcus parvulus, P. pentosaceus, Weissella cibaria, and W. viridescens. 
Fungal species Aspergillus fumigatus, A. brasiliensis DSM1988, A. flavus MUCL11945, Penicillium roqueforti DSM1079, and Gibberella zeae (anamorph Fusarium graminearum) MUCL43764 (Figure 1) were selected as they are either known to produce mycotoxins or are commonly isolated from contaminated baked goods. The method was performed according to Magnusson and Schnurer [33] and Manini, et al. [34] with some modifications. Briefly, the fungal spore suspensions were prepared by growing the molds on a Sabouraud-1\% glucose agar (Dinkelberg Analytics, Gablingen, Germany) for 7 days at $25^{\circ} \mathrm{C}$. Afterwards, conidia were collected by adding $25 \mathrm{~mL}$ of sterile buffered peptone water (Merck, Darmstadt, Germany) to the inoculated agar, horizontally shaking for $10 \mathrm{~min}$ at $50 \mathrm{rpm}$, and inoculating $10 \mathrm{~mL}$ of malt extract soft agar with $1 \mathrm{~mL}$ of a fungal spore-suspension.

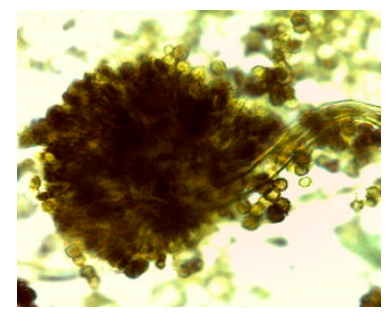

(a)

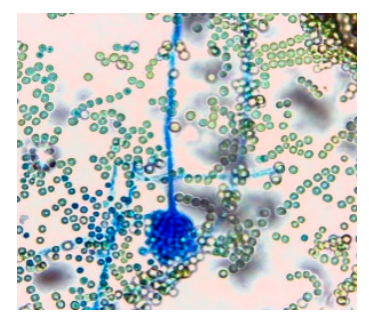

(b)

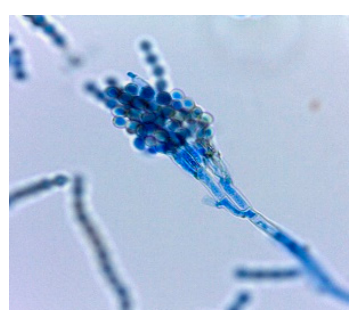

(c)

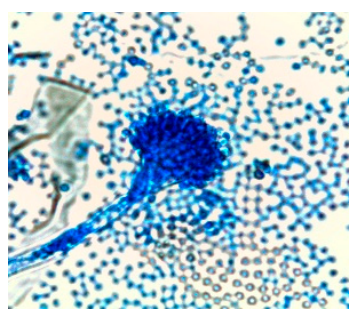

(d)

Figure 1. Asexual reproduction structures of lactophenol cotton blue stained fungal species examined by a light microscope with a total magnification of 1000x; (a) Aspergillus brasiliensis DSM1988, (b) A. flavus MUCL11945, (c) Penicillium roqueforti DSM1079, (d) Aspergillus fumigatus.

Five milliliters of MRS broth were inoculated with the corresponding LAB isolate and incubated for $24 \mathrm{~h}$ at $30^{\circ} \mathrm{C}$ under anaerobic conditions. Further, bacteria were transferred onto the corresponding agar in $2 \mathrm{~cm}$ single lines. After incubation for $48 \mathrm{~h}$, the agar was overlaid with $10 \mathrm{~mL}$ of malt extract soft agar inoculated with fungal spores ( 4 to $5 \log _{10} \mathrm{CFU} \mathrm{mL} \mathrm{m}^{-1}$ ). After incubation at $30{ }^{\circ} \mathrm{C}$ for $48 \mathrm{~h}$, the plates were examined for clear zones around the bacterial lines. The experiment was performed in triplicates. The degree of inhibition was defined as very strong $(+++; \varnothing>8 \mathrm{~mm})$, intermediate $(++; 8 \leq \varnothing<2 \mathrm{~mm})$, weak (+; $\varnothing \leq 2 \mathrm{~mm})$, and no inhibition (-).

To evaluate the synergistic effect of the sodium acetate and the present LAB, isolates exhibiting a very strong inhibition effect, were further tested on an APT agar (Oxoid Ltd., Basingstoke, UK). This medium is especially used for the cultivation of heterofermentative LAB lacking, compared to the MRS agar, sodium acetate, which was determined to have a strong antifungal property itself [35].

\subsection{Determination of Antibacillus Activity by Spot-on-the-Lawn Technique}

The antibacillus activity of 65 LAB isolates was tested against $B$. cereus DSM31, B. licheniformis DSM13, B. subtilis LMG7135, and the sourdough isolate B. subtilis S15.20 in triplicates according to Tremonte, et al. [36] with some modifications. Briefly, the spot-on-the-lawn technique was applied by inoculating Plate Count agar (PCA; Merck, Darmstadt, Germany) plates with spots of $15 \mu \mathrm{L}$ bacterial overnight cultures followed by an incubation for $24 \mathrm{~h}$ at $30^{\circ} \mathrm{C}$ under anaerobic conditions. Each indicator strain was transferred into $10 \mathrm{~mL}$ soft agar $(2 \% v / v)$, before pouring onto PCA plates, on which LAB isolates were grown. After $24 \mathrm{~h}$ at $30^{\circ} \mathrm{C}$, the plates were examined for inhibition zones around the spots. The degree of inhibition was defined as low $(4 \leq \varnothing<12 \mathrm{~mm})$, moderate $(12 \leq \varnothing<20 \mathrm{~mm})$, strong $(20 \leq \varnothing<28 \mathrm{~mm})$, and very strong $(\varnothing \geq 28 \mathrm{~mm})$.

\subsection{Screening of LAB Strains for the Presence of Glutamic Acid Decarboxylase Gene}

The presence/absence of the GAD gene within $179 \mathrm{LAB}$ isolates was evaluated according to Demirbaş, et al. [37]. The bacterial genomic DNA of isolates was isolated as described by Fraberger, Unger, Kummer and Domig [31]. Each PCR mixture $(25 \mu \mathrm{L})$ contained $12.5 \mu \mathrm{L}$ of AccuStart II PCR 
ToughMix (QuantaBio, Beverly, MA, USA) and $20 \mathrm{mM}$ of each primer CoreF (5'-CCTCGAGAAGC CGATCGCTTAGTTCG-3') and CoreR (5'-TCATATTGACCGGTATAAGTGATGCCC-3') [22]. The PCR program was as follows: $95{ }^{\circ} \mathrm{C}$ for $2 \mathrm{~min}, 20$ cycles of $95{ }^{\circ} \mathrm{C}$ for $30 \mathrm{~s}, 60{ }^{\circ} \mathrm{C}$ for $20 \mathrm{~s}$ and $72{ }^{\circ} \mathrm{C}$ for $30 \mathrm{~s}$, followed by a final extension step of $72{ }^{\circ} \mathrm{C}$ for $5 \mathrm{~min}$. Afterwards, PCR products were separated with electrophoresis on $2 \%(w / v)$ agarose-gels at $90 \mathrm{~V}$ for $1.5 \mathrm{~h}$ before staining with GelRed (Biotium, Fremont, CA, USA) and visualized under UV-light. The presence of the GAD gene was indicated by an amplicon size of approximately $540 \mathrm{bp}$.

\subsection{Lactic Acid Bacteria Strain Differentiation}

The repetitive element PCR (rep-PCR) was applied for the genomic characterization of LAB (Table S2) using the single nucleotide primer (GTG) 5 (5'-GTGGTGGTGGTGGTG-3') [38,39]. Amplification was carried out on a Mastercycler nexus SX1 (Eppendorf, Germany) with reaction mixtures $(25 \mu \mathrm{L})$ containing $12.5 \mu \mathrm{L}$ AccuStart II PCR ToughMix (QuantaBio, USA), $11 \mu \mathrm{L}$ ultra-high-quality water, $1 \mu \mathrm{L}$ of primer $(50 \mathrm{pmol} / \mu \mathrm{L})$, and $0.5 \mu \mathrm{L}$ of the DNA template. The following PCR conditions were used: Initial denaturation for $7 \mathrm{~min}$ at $94{ }^{\circ} \mathrm{C}$, followed by 30 cycles of $90{ }^{\circ} \mathrm{C}$ for $30 \mathrm{~s}, 40^{\circ} \mathrm{C}$ for $1 \mathrm{~min}$ and $65^{\circ} \mathrm{C}$ for $8 \mathrm{~min}$, and a final extension of $65^{\circ} \mathrm{C}$ for $16 \mathrm{~min}$. PCR products were electrophoresed in a $2 \%$ agarose-gel for $1 \mathrm{~h}$ and $50 \mathrm{~min}$ before staining with GelRed (Biotium, USA) and visualization under UV light. Resulting fingerprint files were analyzed by the BioNumerics V.8.0 software package and the average linkage (UPGMA) dendogram for LAB was constructed as described by Gevers, Huys and Swings [39].

\subsection{Statistical Analysis}

The statistical analysis was performed using the IBM SPSS Statistics 24.0. The results for the anti-bacillus activity were expressed as the mean $(n=3) \pm$ standard deviation (SD). Data were examined using the one-way analysis of variance (ANOVA). The correlation analysis was performed between the carbohydrate metabolism of LAB and antifungal activity.

\section{Results and Discussion}

\subsection{Strain Differentiation}

In total, $171 \mathrm{LAB}$ isolates of 28 different species were examined by rep-PCR using the (GTG) primer. A detailed list of the number of isolates per species and isolate code is illustrated in Table S2. Differences on the strain level were observed between isolates within the species Enterococcus hirae, Levilactobacillus brevis, Lev. senmaizukei, Loigolactobacillus coryniformis, Latilactobacillus curvatus, Lacticaseibacillus paracasei, Lactiplantibacillus plantarum, Fructilactobacillus sanfranciscensis, and Weissella cibaria. As exemplary illustrated for the species Lp. plantarum (Figure 2), the (GTG) $)_{5}$ PCR fingerprinting and cluster analysis separated the analyzed strains into seven groups according to their similarity. Strains S10.13, S10.19, and S5.16 showed 100\% similarity. This result is reflected to those received for the antimicrobial activity and absence/presence of the GAD gene.

\subsection{Carbohydrate Metabolism}

The carbohydrate fermentation profile of LAB isolates regarding wheat relevant carbohydrates [32] was evaluated as LAB cell counts and, therefore, sensory and functional attributes are depending on the present strains and available carbohydrates. The metabolism profiles are illustrated in Table S1. According to our results, the tested microorganisms favored glucose, maltose, and fructose as these sole carbon sources were utilized by $99 \%, 94 \%$, and $89 \%$ of the tested isolates, respectively. These data were in accordance with the information received by Manini, Casiraghi, Poutanen, Brasca, Erba and Plumed-Ferrer [34] as seven typical sourdough species analyzed regarding their carbohydrate fermentation profile showed the fermentation of D-glucose, D-fructose, and D-maltose. Regarding Enterococcus strains, the majority exhibited growth on each of the tested carbohydrates, 
except for TS4.8, which did not grow on sucrose, and TS4.1, which exhibited no growth on raffinose. Concerning Leuconostoc spp., all tested strains metabolized the applied sugars, except for TS2.8, which did not utilize raffinose as a sole carbohydrate. P. pentosaceus strains fermented fructose, glucose, and maltose, except for isolate S10.10, which could not utilize fructose. Variable fermentation profiles were obtained for $38 \%$ of P. pentosaceus isolates due to the inability to grow on maltodextrin, raffinose, or sucrose.
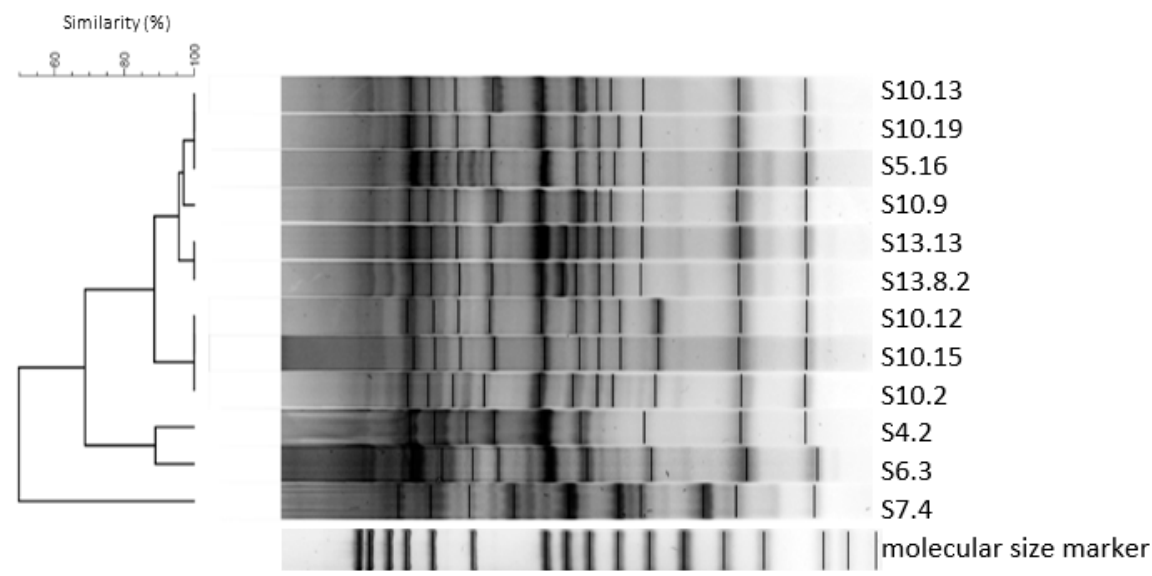

Figure 2. Dendogram based on the cluster analysis of (GTG) 5 -PCR fingerprints from Lactiplantibacillus plantarum isolated from sourdough.

All examined lactobacilli except for Fr. sanfranciscensis TS7.3 and Len. otakiensis S3.11 exhibited a very strong or strong growth on D-(+)-glucose as a sole carbohydrate source. The species $\mathrm{Pa}$. vaccinostercus, Co. paralimentarius, and Lat. sakei, as well as the isolate Len. otakiensis S3.1 showed no growth on D-(+)-maltose. However, other tested Len. otakiensis isolates (S3.11, S3.15) were able to grow. D-(-)-fructose as a sole carbohydrate source was not metabolized by any isolates belonging to the species Co. kimchii, Co. paralimentarius, Fr. sanfranciscensis, and Pa. vaccinostercus. Further, Lp. plantarum S7.4 was not able to ferment fructose. The growth of lactobacilli on maltodextrin as a sole carbohydrate resulted in either poor or no growth of $68 \%$ of the tested isolates, which was even evaluated by Watson, et al. [40]. The tested Lev. brevis isolates and the majority of $L p$. plantarum strains (78\%) metabolized maltodextrin. Only one strain of La. curvatus and Lo. coryniformis exhibited strong growth. Within the species La. curvatus, isolates TS4.11 and S5.7.1 were the only tested ones exhibiting the potential to strongly grow on maltodextrin. Raffinose was metabolized by $46 \%$, and sucrose by $84 \%$ of the tested LAB isolates. These results showed a high variability within the tested lactobacilli, which derived from its high phylogenetic diversity [41].

Due to the examination of preferred carbon sources, even differences on the strain level were observed. Fructose belongs to the group of FODMAPs (fermentable oligo-, di-, monosaccharides, and polyols), being an important player in the clinical picture of NCWS (non-celiac-wheat-sensitivity). Furthermore, it is a metabolic product of fructan, which is assumed to be the main trigger of NCWS. This study showed the potential of the majority of sourdough LAB to degrade fructose. Therefore, a synergistic effect with specific fructan degrading yeasts [42] could lead to well-tolerated bakery products.

\subsection{Antifungal Activity}

The molds evaluated in this study, Aspergillus brasiliensis, A. fumigatus, A. flavus, Penicillium roqueforti, and Fusarium graminearum, can contaminate several agricultural products and are capable of producing mycotoxins and allergenic spores, decreasing the nutritional value, and leading to economic losses [43-45]. Therefore, technological, economic, and health reasons lead to the necessity of bakery products exhibiting a high antimicrobial activity, in which consumers' demand is going 
towards less application of chemical preservatives. To compensate the use of, for example, propionic, benzoic, and sorbic acids and some of their salts, research on the applicability of sourdough as a natural alternative was addressed by several studies [8,45-47]. Hence, the antifungal activity of LAB strains typically present in sourdough was evaluated against Aspergillus fumigatus, A. flavus, A. brasiliensis, Penicillium roqueforti, and Fusarium graminearum. LAB exhibited varying levels of inhibition against the five fungal indicator strains. In turn, the fungi displayed a different degree of sensitivity against the producer strains. Table 2 illustrates the results obtained by determining the antifungal activity using MRS and APT agar. An examination of MRS agar plates showed that F. graminearum MUCL43764 exhibited the highest sensitivity, being very strongly inhibited $(+++; \varnothing>8 \mathrm{~mm})$ by $96 \%$ of the tested LAB isolates, followed by $A$. fumigatus with $55 \%$ of LAB showing a very strong inhibition potential. Pe. roqueforti DSM1079 manifested the highest resistance, as 65\% of the LAB isolates did not alter the growth capability of this fungus, followed by A. flavus MUCL11945 (28\%).

Results showed the potential to inhibit mold growth for the majority of the LAB isolates tested. However, the intensity was highly dependent on the LAB strain and the fungal species. Already, Gerez, Torino, Rollán and Font de Valdez [45] revealed the strain dependency on the inhibition of fungal growth. Schwenninger, et al. [48] examined the inhibitory potential of lactobacilli against Penicillium sp., showing strain differences regarding the acid production of species belonging to the former L. casei group. In the present study, isolates of the species Lev. brevis, Lo. coryniformis, Len. parabuchneri, Lp. plantarum, Fu. rossiae, Fr. sanfranciscensis, L. paracasei, Lev. senmaizukei, Lev. spicheri, and P. pentosaceus revealed a different inhibition potential against Pe. roqueforti DSM1079. A very strong inhibition was observed for Lev. brevis S4.5, Lo. coryniformis S4.4.2, Lp. plantarum S4.2, Len. parabuchneri S2.9, and L. paracasei S9.11, whereas Lev. brevis S13.18, S14.3, and S6.13 did not inhibit the growth of Pe. roqueforti DSM1079. In contrast to our study, Magnusson, et al. [49] did not prove an inhibitory effect against $P e$. roqueforti.

Within this study, Lp. plantarum exhibited the highest antifungal potential against the indicator strains. This species is known for the production of PLA, p-hydroxyphenyllactic acid, palmitic acid [50], and low molecular peptides [51] exhibiting an antifungal activity. Studies on the inhibition potential of L p. plantarum in bread revealed a complete inhibition of Fusarium sp. and a reduced growth of Pe roqueforti and $A$. niger on the contaminated bread [52]. Furthermore, a positive effect of Lp. plantarum and even $L$. paracasei strains towards the reduction of mycotoxins has already been observed by Bartkiene, et al. [53]. Within our study, each tested L. paracasei strain exhibited a very strong inhibition against F. graminearum MUCL43764, which was observed even by Hassan and Bullerman [54].

Lp. plantarum S4.2 and Len. parabuchneri S2.9 exhibited the highest inhibition (very strong or intermediate) against the indicator strains when using the MRS medium. As observable for the analyzed species, differences of inhibition were determined, leading to the conclusion that the antifungal activity was mainly strain dependent. For example, Lev. brevis S13.18 and S14.3 did not inhibit the growth of Pe. roqueforti DSM1079. However, Lev. brevis S3.5 exhibited intermediate and Lev. brevis S4.5 an even strong inhibition potential. 
Table 2. Antifungal activity of lactic acid bacteria exerted on MRS (de MAN, ROGOSA and SHARPE; left of the vertical bar) and APT (all-purpose tween; right of the vertical bar) medium against Aspergillus brasiliensis DSM1988, A. fumigatus, Penicillium roqueforti DSM1079, Fusarium graminearum MUCL43764, and A. flavus MUCL11945.

\begin{tabular}{|c|c|c|c|c|c|c|c|c|c|c|c|}
\hline \multicolumn{12}{|c|}{ Antifungal Performance on MRS|APT Medium ${ }^{1}$} \\
\hline Isolate & $\begin{array}{c}A . \\
\text { brasiliensis } \\
\text { DSM1988 }\end{array}$ & $\begin{array}{c}\text { A. } \\
\text { fumigatus }\end{array}$ & $\begin{array}{c}\text { Pe. } \\
\text { roqueforti } \\
\text { DSM1079 }\end{array}$ & $\begin{array}{c}F . \\
\text { graminearum } \\
\text { MUCL43764 }\end{array}$ & $\begin{array}{c}\text { A. flavus } \\
\text { MUCL11945 }\end{array}$ & Isolate & $\begin{array}{c}\text { A. } \\
\text { brasiliensis } \\
\text { DSM1988 }\end{array}$ & $\begin{array}{c}\text { A. } \\
\text { fumigatus }\end{array}$ & $\begin{array}{c}\text { Pe. } \\
\text { roqueforti } \\
\text { DSM1079 }\end{array}$ & $\begin{array}{c}F . \\
\text { graminearum } \\
\text { MUCL43764 }\end{array}$ & $\begin{array}{c}\text { A. flavus } \\
\text { MUCL11945 }\end{array}$ \\
\hline Co. paralimentarius S7.5 & ++ & $+++\mid-$ & $-1-$ & $+++\mid-$ & $-1-$ & Len. parabuchneri S2.16 & $++\mid-$ & $+++\mid-$ & $+1-$ & $+++\mid+$ & +++- \\
\hline Fr. sanfranciscensis S18.5 & +++- & $+++\mid+$ & $+1-$ & $+++\mid+++$ & ++- & Len. parabuchneri S2.9 & +++- & +++- & +++- & $+++\mid++$ & ++- \\
\hline Fr. sanfranciscensis TS6.5 & $-1-$ & -- & $-1-$ & $+++\mid-$ & -1 & Lev. brevis S13.18 & $++\mid-$ & +++- & -- & +++- & $++1-$ \\
\hline Fr. sanfranciscensis TS6.7 & -1 & $-1-$ & -1 & +++- & $-1-$ & Lev. brevis $\mathrm{S} 14.3$ & ++- & +++- & $-1-$ & $+++\mid++$ & $+1-$ \\
\hline Fr. sanfranciscensis TS7.3 & $-1-$ & + & -1 & $+++\mid+++$ & ++- & Lev. brevis S3.5 & +++- & +++- & ++- & $+++\mid+++$ & -1 \\
\hline Fr. sanfranciscensis S11.7 & $-1-$ & $-1+$ & -1 & $+++\mid+++$ & ++- & Lev. brevis $\mathrm{S} .5$ & $++\mid-$ & +++- & +++- & $+++\mid+++$ & $-1-$ \\
\hline Fu. rossiae S1.10 & ++- & +++- & $+1-$ & $+++\mid++$ & ++- & Lev. brevis $\mathrm{S} 6.13$ & +++- & $++\mid-$ & $-1-$ & ++++ & $-1-$ \\
\hline Fu. rossiae S1.21 & $+1-$ & $++\mid-$ & $-1-$ & $+++\mid+++$ & $+1-$ & Lev. hammesii S14.1 & $++\mid-$ & +++- & +++ & +++++ & ++- \\
\hline Fu. rossiae S2.4 & ++- & +++- & ++- & $+++\mid+++$ & $+1-$ & Lev. kimchii S7.10 & $+\mid-$ & +- & $-1-$ & $+++\mid+++$ & $+1-$ \\
\hline La. curvatus S4.1 & $+1-$ & +- & $-1-$ & n.a. ${ }^{2}$ & n.a. ${ }^{2}$ & Lev. senmaizukei S4.24 & ++- & ++- & $-1-$ & $+++\mid+++$ & ++- \\
\hline La. curvatus S4.14 & $-1-$ & $-1-$ & $-1-$ & +++- & $-1-$ & Lev. senmaizukei S4.27 & +++- & +++- & $-1-$ & $+++\mid+++$ & $+1-$ \\
\hline La. curvatus S5.22 & -1 & -1 & -1 & +++- & $-\mid$ & Lev. senmaizukei S5.18 & +- & +++- & ++- & $+++\mid+++$ & $+1-$ \\
\hline La. curvatus S6.15 & -1 & -1 & -1 & +++- & -1 & Lev. senmaizukei S6.21 & ++- & $++\mid-$ & -1 & $+++\mid+++$ & $+1-$ \\
\hline L. paracasei $\mathrm{S} 2.21$ & $+1-$ & $-1-$ & -1 & +++- & -1 & Lev. spicheri S4.26 & $++1-$ & +++- & -1 & +++|+++ & ++- \\
\hline L. paracasei $\mathrm{S} 8.13$ & $+1-$ & +++- & + & +++- & ++- & Lev. spicheri S6.10 & $+1-$ & $++\mid-$ & $-1-$ & ++++ & $+\mid-$ \\
\hline L. paracasei S8.18 & $-1-$ & $-1-$ & $+1-$ & ++++ & -1 & Lev. spicheri S13.10 & ++- & +++- & ++- & $\begin{array}{ll}+++++ \\
++\end{array}$ & $+1-$ \\
\hline L. paracasei S8.21 & ++- & +++- & $-1-$ & $+++\mid++$ & + & Li. pontis $\mathrm{S} 15.14$ & -1 & $-1-$ & -1 & -1 & $-1-$ \\
\hline L. paracasei $\mathrm{S} 8.24$ & ++- & $++\mid-$ & -1 & +++- & $+1-$ & Li. pontis S15.3 & $-1-$ & $-1-$ & $-1-$ & $-1-$ & $-1-$ \\
\hline L. paracasei S8.3 & ++- & +++- & -1 & +++- & ++- & Li. pontis S2.25 & ++- & +++- & $-1-$ & $+++\mid+++$ & ++- \\
\hline L. paracasei $\mathrm{S} 8.8$ & ++- & $++\mid-$ & -1 & +++- & $+1-$ & Lo. coryniformis S4.16 & ++- & +++- & $-1-$ & $+++\mid+$ & ++- \\
\hline L. paracasei $\mathrm{S} 9.11$ & -1 & $+1-$ & +++- & +++- & $+1-$ & Lo. coryniformis $\mathrm{S} 4.23$ & $+1-$ & $++\mid-$ & $-1-$ & $+++\mid++$ & $-1-$ \\
\hline L. paracasei S9.15 & +- & +++- & $-1-$ & +++- & $+1-$ & Lo. coryniformis S4.4.2 & ++- & ++- & +++- & n.a. ${ }^{2} \mid+++$ & n.a. ${ }^{2}$ \\
\hline L. paracasei S9.18 & $+1-$ & +++- & -1 & ++++ & $+1-$ & Lo. coryniformis $\mathrm{S} 5.20$ & $+\mid-$ & ++- & $-1-$ & +++++ & $+\mid-$ \\
\hline L. paracasei $\mathrm{S} 9.20$ & + & $++\mid-$ & $-1-$ & ++++ & ++- & Lo. coryniformis S6.9.1 & $-1-$ & ++- & $-\mid$ & +++++ & $+1-$ \\
\hline L. paracasei S9.24 & $-1-$ & +++- & $-1-$ & +++- & $+1-$ & Lp. plantarum $\mathrm{S} 13.8 .2$ & ++ & +++- & $+1-$ & +++- & -1 \\
\hline L. paracasei S9.3 & $-1-$ & $++\mid-$ & $-1-$ & +++- & ++- & Lp. plantarum S4.2 & +++- & +++- & +++- & $+++\mid+++$ & ++- \\
\hline L. paracasei S9.8 & $-1-$ & +++- & $-1-$ & $+++\mid+$ & $+\mid-$ & Lp. plantarum S5.16 & $+1-$ & +++- & $-1-$ & +++++ & ++- \\
\hline Lat. sakei S4.19 & $-1-$ & -1 & $-1-$ & +++- & $-1-$ & Lp. plantarum S6.3 & ++- & +++- & $+1-$ & $+++\mid+++$ & $+1-$ \\
\hline Len. diolivorans S3.2 & $+1-$ & + & $+1-$ & $+++\mid++$ & ++ & Lp. plantarum S7.4 & -1 & +++- & $-1-$ & +++- & -1 \\
\hline Len. kisonensis S3.10 & $+1-$ & $++1-$ & $+1-$ & $+++\mid++$ & +- & Lp. plantarum $\mathrm{S} 10.12$ & ++- & +++- & ++ & +++++ & ++- \\
\hline Len. kisonensis S3.4 & +++- & +++- & $+1-$ & +++++ & ++- & Lp. plantarum S10.13 & $+1-$ & +++- & ++- & +++++ & ++- \\
\hline Len. otakiensis S3.15 & $-1-$ & $-1-$ & $-1-$ & +++- & -1 & Lp. plantarum S10.15 & $+1-$ & +++- & ++ & ++++++ & ++ \\
\hline Lp. plantarum S10.19 & ++ & +++- & $-1-$ & $+++\mid++$ & ++- & P. pentosaceus $\mathrm{S} 10.10$ & ++- & +++- & +- & $+++1++$ & $-1-$ \\
\hline Lp. plantarum $\mathrm{S} 10.2$ & ++- & +++- & $-1++$ & +++++ & $+1-$ & P. pentosaceus S10.11 & ++- & +++- & $+1-$ & ++++ & $+1-$ \\
\hline Lp. plantarum S10.9 & ++- & +++- & $+1-$ & $+++\mid++$ & $+1-$ & P. pentosaceus $\mathrm{S} 10.22$ & ++- & $++\mid-$ & -1 & +++++ & ++- \\
\hline Lp. plantarum S13.13 & +++- & +++- & $+1-$ & ++++++ & ++- & P. pentosaceus S5.19 & ++- & ++- & $-1-$ & $+++\mid+++$ & $+1-$ \\
\hline Lp. xiangfangensis S7.11 & $++1-$ & +++- & $-1-$ & $+++\mid++$ & $+1-$ & W. cibaria S10.4 & ++- & +++- & $-1++$ & ++++++ & +- \\
\hline Pa. vaccinostercus S6.20 & $-1-$ & - & $-1-$ & $-1-$ & -1 & W. viridescens S2.3 & $++1-$ & +++- & $-1-$ & $+++\mid+++$ & ++- \\
\hline
\end{tabular}

1 Inhibition was scored as follows: +++ Very strong inhibition with large clear halos $(\varnothing>8 \mathrm{~mm})$ around the colonies; ++ intermediate inhibition with small clear halos $(8 \leq \varnothing<2 \mathrm{~mm})$ around the spots; + weak inhibition around spots $(\varnothing \leq 2 \mathrm{~mm})$; - no inhibition; ${ }^{2}$ n.a.: Not analyzed. 
Repeating the series of experiments on the APT medium showed a highly decreased activity by all isolates. The tested LAB isolates did not show any inhibitory effect against A. brasiliensis DSM1988 and A. flavus MUCL11945. Fr. sanfranciscensis S11.7 and S18.5 exhibited a weak degree of inhibition (0.5 to $1 \mathrm{~mm}$ ) against $A$. fumigatus. Pe. roqueforti DSM1079 was inhibited only by Lp. plantarum S10.2 (intermediate), S10.12 and S10.14 (weak), Lev. hammesii S14.1 and W. cibaria S10.4 exhibited an intermediate inhibition. As already observable on MRS agar, F. graminearum exhibited the highest sensitivity also on the APT medium. Overall, results strongly suggest that the MRS medium exhibits superior properties to stimulate the production of antifungal compounds. This fact was observed even by Gajbhiye and Kapadnis [55], who concluded that glucose optimized the antifungal activity. Furthermore, within this study, a potential correlation between carbohydrates as sole carbon sources and the antifungal activity of the tested LAB strains was observable for glucose, fructose, sucrose, and raffinose regarding the inhibition of $A$. fumigatus, as well as the tested carbohydrates and the inhibition of $A$. brasiliensis DSM1988 and Pe. roqueforti DSM1079 (Table S3). Further, Gerez, Torino, Rollán and Font de Valdez [45] investigated the major antifungal compounds of Lp. plantarum, Li. reuteri, and Lev. brevis strains inhibiting fungal growth in bread. Results within this study revealed acetic and phenyllactic acids (PLA) as main antifungal components. The efficiency of organic acids was dependent on the $\mathrm{pH}$ values. Due to a lower $\mathrm{pH}$ value, the rate of a more hydrophobic, undissociated form of lactic acid increased. This form can easily enter the cell by crossing the cell membrane, releasing $\mathrm{H}^{+}$-ions and acidifying the cytoplasm. Hence, leading to the loss of viability and demolition of the cell $[45,56]$.

\subsection{Antibacilli Activity}

Bacilli are important spoilage organisms in bakery products as previous studies showed the development of rope spoilage, leading to a fruity odor after $12 \mathrm{~h}$ [57]. Therefore, the objective of this study was to investigate in vitro the potential of 65 LAB isolated from sourdough to inhibit spoilage bacilli and, hence, be used as future bio preservatives in wheat-based bakery products. Results showed varying levels of inhibition against the four tested indicator strains (Figure 3a-f). In turn, the bacilli displayed a different degree of sensitivity against the LAB isolates, in which the sourdough isolate B. subtilis S15.20 displayed the highest resistance against inhibition (11\%), compared to the strain B. subtilis LMG7135 exhibiting resistance only against 9\% of the tested isolates. Moreover, $94 \%$ of LAB inhibited the growth of B. cereus DSM31, and 98\% showed activity against B. licheniformis DSM13. In addition to L. paracasei, Lp. plantarum strains showed increased inhibitory effects against bacilli. However, the ability of a species to suppress the growth of Bacillus spp. was shown to be strain dependent. These data are in accordance with results reported by Arena, et al. [58], in which the production of antimicrobial compounds varied between Lp. plantarum strains. In general, Lp. plantarum S6.3 and S10.12 exhibited the highest inhibitory capability (ø $23 \mathrm{~mm}$ ) against B. cereus DSM31. L. paracasei S8.13 and S9.11, Lp. plantarum S13.13, and Fr. sanfranciscensis S18.5 showed a strong inhibition (ø $23 \mathrm{~mm}$ ) against B. licheniformis DSM13. B. subtilis strains were especially sensitive (ø $17 \mathrm{~mm}$ ) against Lo. coryniformis S6.9.1 and S4.23, as well as Fr. sanfranciscensis TS6.7 and S18.5. B. subtilis S15.20 against Lp. plantarum S10.15.

Already, Mantzourani, et al. [59] tested the capacity of L. paracasei strains to delay the growth of Bacillus spp. in bread samples, showing a later appearance of rope spoilage in sourdough breads prepared with the addition of L. paracasei, compared to the control breads. The results derived within our study, are in accordance with the previous mentioned investigation [59], as a strong inhibitory effect of the tested L. paracasei strains against bacilli strains was observable. Lactic and acetic acid belong to the main inhibitory substances produced by LAB. However, further antimicrobials such as hydrogen peroxide, diacetyl, bacteriocins, and bacteriocin-like inhibitory substances (BLIS) can play important roles in inhibiting Bacillus spp. [60]. 


\subsection{Determination of the GAD Gene}

The most common way by many LAB to produce GABA is via the glutamic acid decarboxylase (GAD) system [23]. Therefore, sourdough isolates were screened for the presence of the GAD gene. Within our study, $25 \%$ of the tested isolates gave a PCR product of approximately $540 \mathrm{bp}$, including strains of Lev. brevis, Lo. coryniformis, Lp. plantarum, Lev. senmaizukei, Lev. hammesii, and L. paracasei. Further, a strain-dependency was observed for the presence of the GAD gene. For instance, only isolate Lo. coryniformis S4.4.2 gave a band with the primer set CoreF and CoreR. Compared to the outcomes of the study performed by Wu, Tun, Law, Khafipour and Shah [23] a strain-dependent presence of the GAD gene was even observed for Lev. brevis. Due to the beneficial physiological functions of GABA on human health, this bioactive component is extensively used for producing functional foods and its concentration has already been reported in several fermented foods [26]. Our results demonstrated that only part of the sourdough isolates exhibit the GAD gene, and hence a potential to produce GABA, which was even demonstrated by Villegas, et al. [61]. However, a further analysis is necessary to clearly state a possible GABA production and further quantify the yield obtained by the application of specific LAB isolates. Hence, this study is the starting point to determine isolates, which could contribute to the development of fermented foods with increased functional properties.

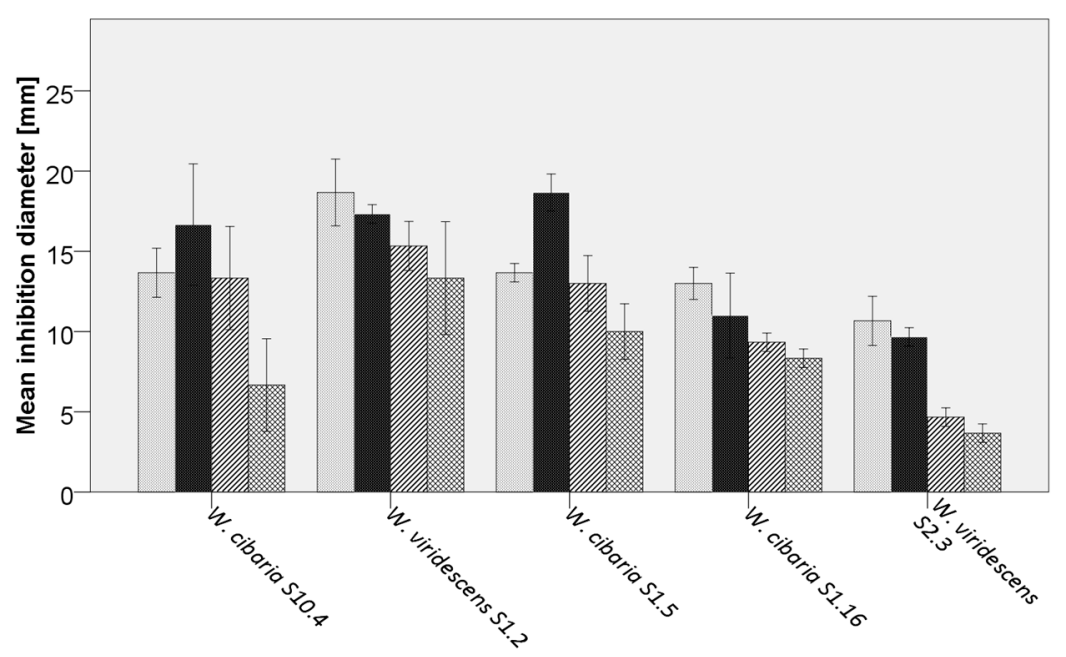

(a)

Figure 3. Cont. 


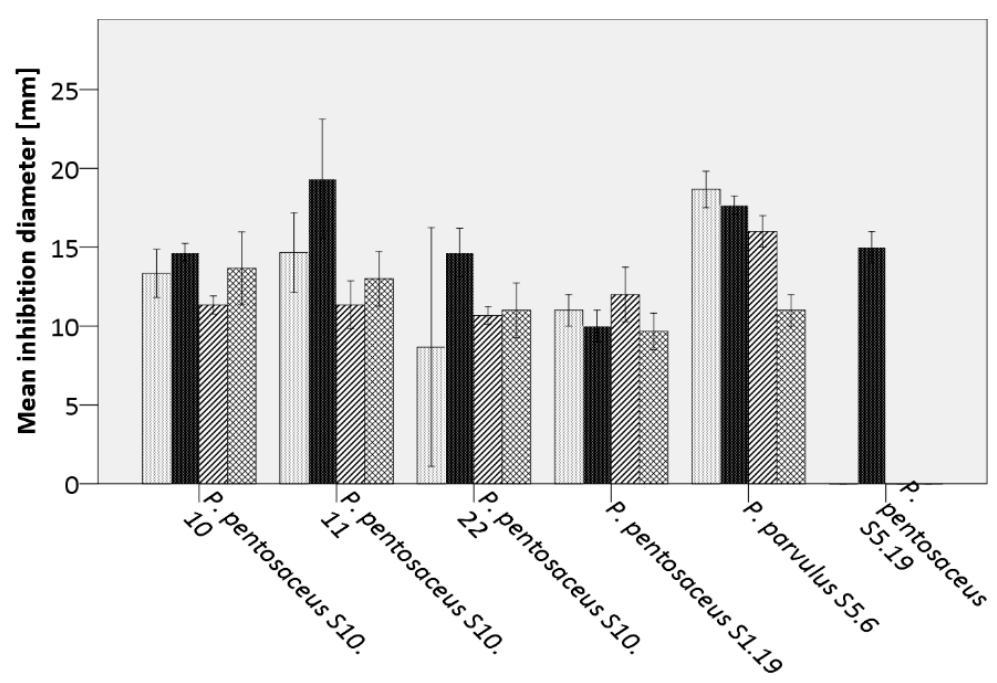

(b)

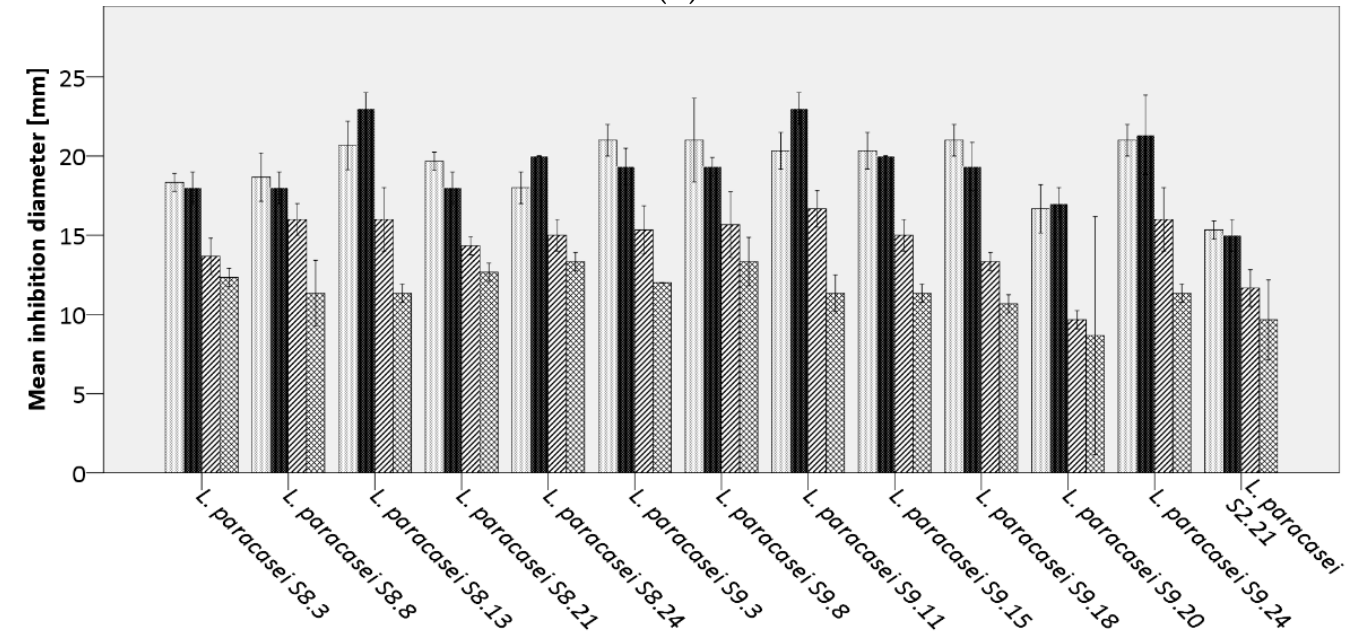

(c)

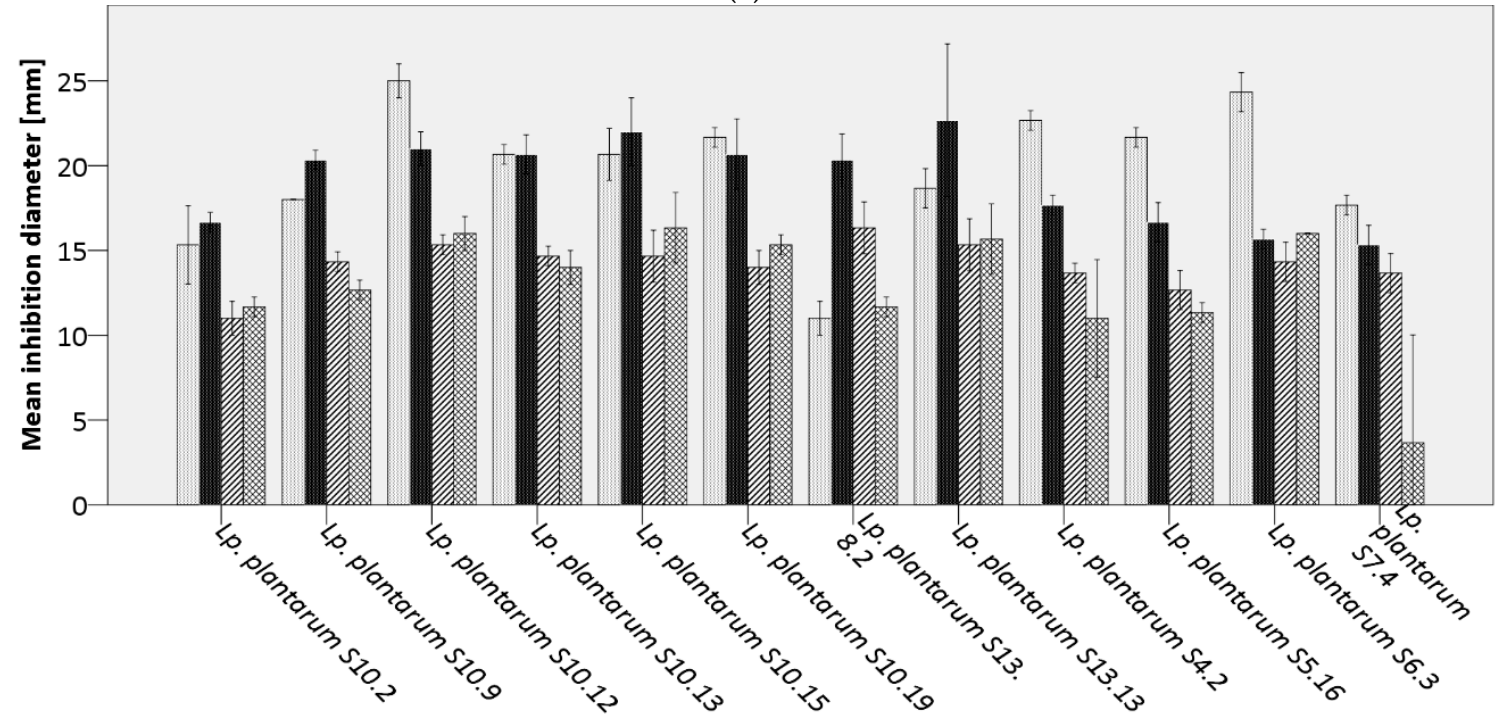

(d)

Figure 3. Cont. 


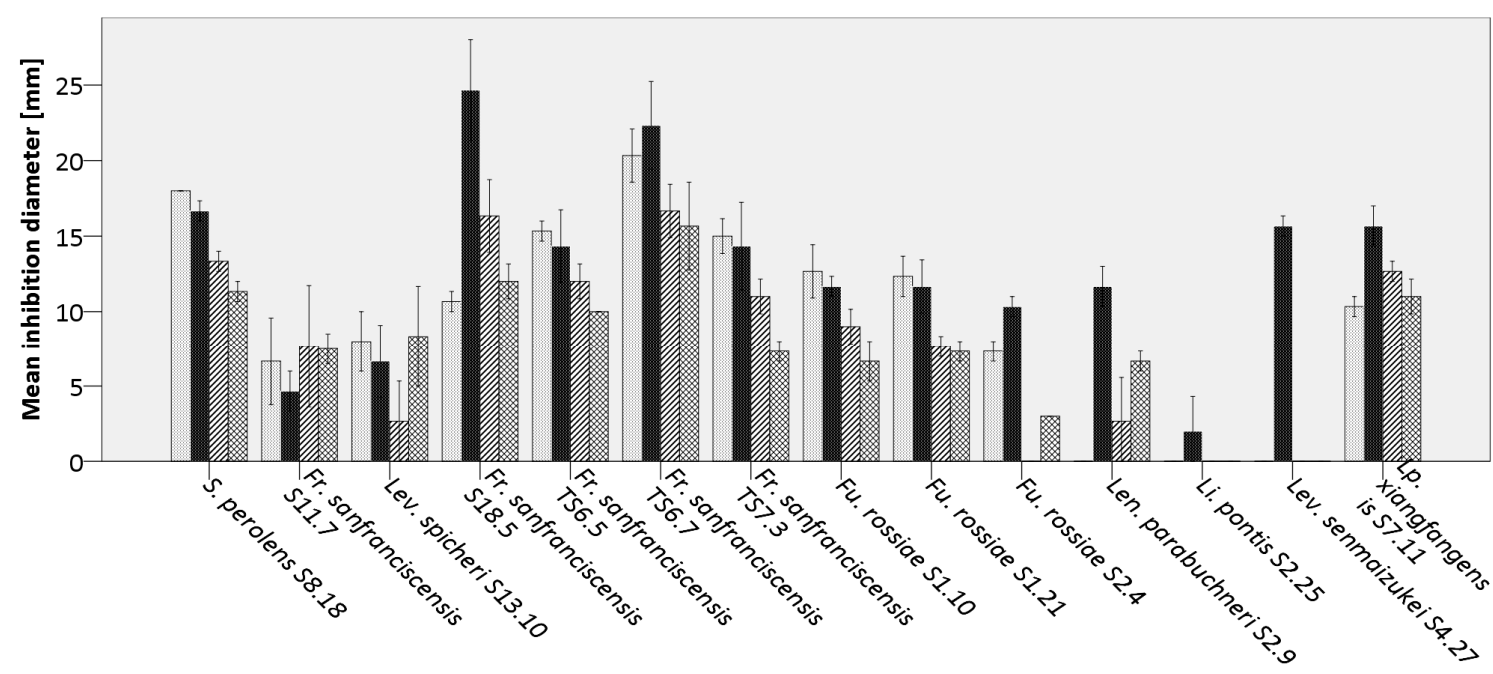

(e)

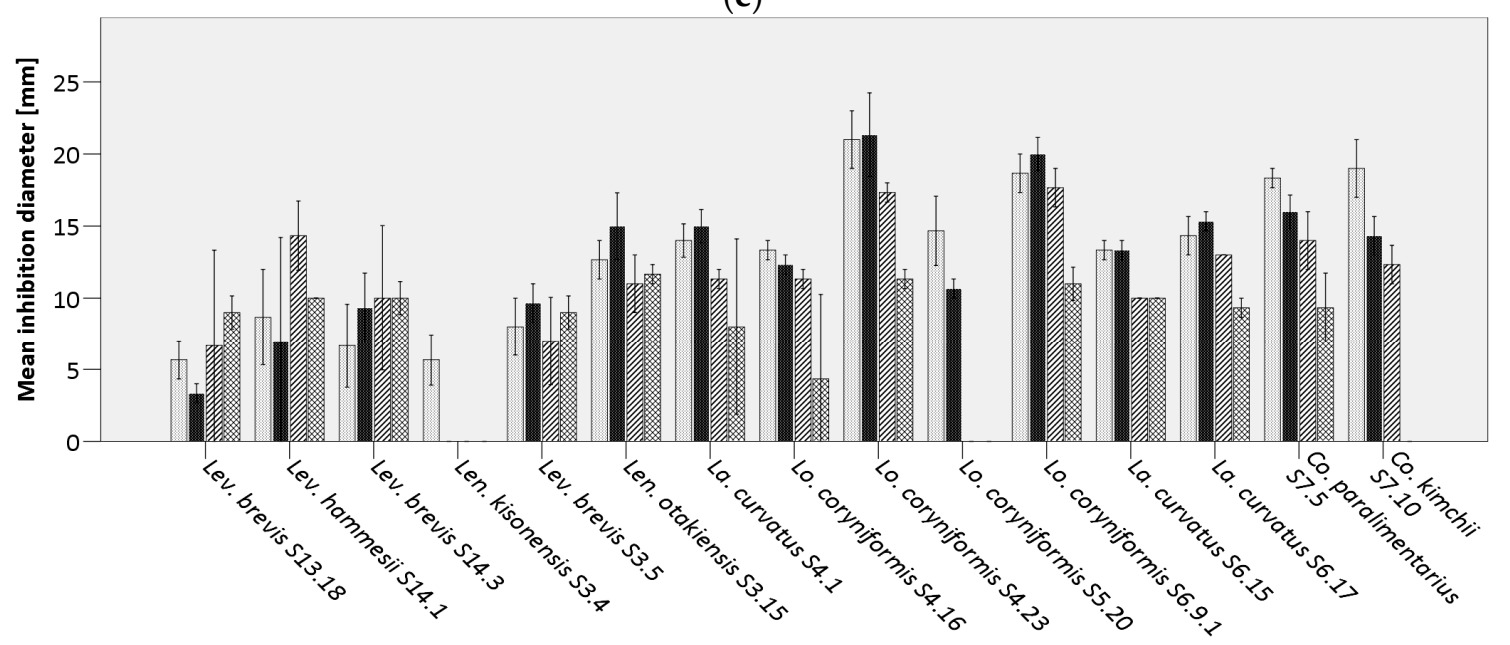

(f)

Figure 3. Average inhibition of analyzed lactic acid bacteria (LAB) against 0 Bacillus cereus DSM31,

B. licheniformis DSM13, $\mathbb{Z}$ B. subtilis LMG7135, and B. subtilis S15.20, by (a) Weissella spp.,

(b) Pediococcus spp., (c) Lacticaseibacillus paracasei, (d) Lactiplantibacillus plantarum, (e,f) further lactobacilli.

\section{Conclusions}

In this study, LAB strains isolated from sourdough were characterized regarding their carbohydrate metabolism, antimicrobial potential, and presence/absence of the GAD gene. Interestingly, most LAB strains exhibited an inhibitory potential against the tested molds and bacilli. However, the main antifungal components within this study still remain unknown. Therefore, further studies are necessary. The preferred carbon source within the tested lactobacilli reflected its high phylogenetic diversity. Further, a strain-dependent utilization was observed. Although there was no unique LAB strain possessing the GAD gene and the highest inhibitory potential, further studies could allow the assessment of the safe use of single or combined LAB isolates as (i) food bio-preservatives, (ii) food fermentation starters, and (iii) co-players in producing enhanced functional properties and high-quality low FODMAPs bakery products of improved quality.

Supplementary Materials: The following are available online at http://www.mdpi.com/2076-2607/8/12/ 1895/s1. Figure S1: Evaluation of antimicrobial potential of Loigolactobacillus coryniformis S4.23 against (a) Aspergillus fumigatus using the cultural overlay assay, and (b) Bacillus cereus DSM31 using the spot-on-the-lawn technique; Table S1: Carbohydrate metabolism of lactic acid bacteria isolated from sourdough evaluated by 
$\mathrm{OD}_{620}$ measurements; Table S2. LAB isolates used for genomic strain differentiation by the repetitive element PCR; Table S3: Correlation coefficients of growth applying different carbohydrate sources on the inhibition of fungal activity.

Author Contributions: V.F. and K.J.D. conceived and designed the methodology and conceptualization; C.A. and V.F. performed the microbiological analysis and conducted data analysis; V.F. wrote the initial draft of the manuscript; K.J.D. reviewed the final paper; V.F. wrote and submitted the final paper. All authors have read and agreed to the published version of the manuscript.

Funding: This research did not receive any specific grant from funding agencies in the public, commercial, or not-for-profit sectors.

Acknowledgments: The authors thank the EQ BOKU VIBT GmbH-Core Facility Food \& Bio Processing for providing the MALDI-TOF mass spectrometer (Bruker Biotyper) for bacteria identification. The authors gratefully acknowledge Cost Action CA18101 SOURDOMICS "SOURDOugh biotechnology network towards novel, healthier and sustainable food and bIoproCesseS".

Conflicts of Interest: The authors declare no conflict of interest.

\section{References}

1. Asioli, D.; Aschemann-Witzel, J.; Caputo, V.; Vecchio, R.; Annunziata, A.; Naes, T.; Varela, P. Making sense of the "clean label" trends: A review of consumer food choice behavior and discussion of industry implications. Food Res. Int. 2017, 99, 58-71. [CrossRef]

2. Ricci, A.; Bernini, V.; Maoloni, A.; Cirlini, M.; Galaverna, G.; Neviani, E.; Lazzi, C. Vegetable by-product lacto-fermentation as a new source of antimicrobial compounds. Microorganisms 2019, 7, 607. [CrossRef]

3. Gänzle, M.G.; Zheng, J. Lifestyles of sourdough lactobacilli - Do they matter for microbial ecology and bread quality? Int. J. Food Microbiol. 2019, 302, 15-23. [CrossRef] [PubMed]

4. Gobbetti, M. The sourdough microflora: Interactions of lactic acid bacteria and yeasts. Trends Food Sci. Technol. 1998, 9, 267-274. [CrossRef]

5. Corsetti, A.; Settanni, L. Lactobacilli in sourdough fermentation. Food Res. Int. 2007, 40, 539-558. [CrossRef]

6. Brandt, M.J.; Gänzle, M. Handbuch Sauerteig; Behr: Hamburg, Germany, 2006.

7. Chen, C.C.; Lai, C.C.; Huang, H.L.; Huang, W.Y.; Toh, H.S.; Weng, T.C.; Chuang, Y.C.; Lu, Y.C.; Tang, H.J. Antimicrobial activity of Lactobacillus species against Carbapenem-resistant Enterobacteriaceae. Front. Microbiol. 2019, 10, 789. [CrossRef] [PubMed]

8. Quattrini, M.; Liang, N.; Fortina, M.G.; Xiang, S.; Curtis, J.M.; Ganzle, M. Exploiting synergies of sourdough and antifungal organic acids to delay fungal spoilage of bread. Int. J. Food Microbiol. 2019, 302, 8-14. [CrossRef] [PubMed]

9. Rosenkvist, H.; Hansen, A. Contamination profiles and characterisation of Bacillus species in wheat bread and raw materials for bread production. Int. J. Food Microbiol. 1995, 26, 353-363. [CrossRef]

10. Mantzourani, I.; Plessas, S.; Saxami, G.; Alexopoulos, A.; Galanis, A.; Bezirtzoglou, E. Study of kefir grains application in sourdough bread regarding rope spoilage caused by Bacillus spp. Food Chem. 2014, 143, 17-21. [CrossRef]

11. Şimşek, Ö.; Çon, A.H.; Tulumog`lu, Ş. Isolating lactic starter cultures with antimicrobial activity for sourdough processes. Food Control. 2006, 17, 263-270. [CrossRef]

12. Garofalo, C.; Zannini, E.; Aquilanti, L.; Silvestri, G.; Fierro, O.; Picariello, G.; Clementi, F. Selection of sourdough lactobacilli with antifungal activity for use as biopreservatives in bakery products. J. Agric. Food Chem. 2012, 60, 7719-7728. [CrossRef]

13. Sadeghi, A.; Ebrahimi, M.; Mortazavi, S.A.; Abedfar, A. Application of the selected antifungal LAB isolate as a protective starter culture in pan whole-wheat sourdough bread. Food Control. 2019, 95, 298-307. [CrossRef]

14. Sadeghi, A.; Ebrahimi, M.; Raeisi, M.; Nematollahi, Z. Biological control of foodborne pathogens and aflatoxins by selected probiotic LAB isolated from rice bran sourdough. Biol. Control. 2019, 130, 70-79. [CrossRef]

15. Fekri, A.; Torbati, M.; Yari Khosrowshahi, A.; Bagherpour Shamloo, H.; Azadmard-Damirchi, S. Functional effects of phytate-degrading, probiotic lactic acid bacteria and yeast strains isolated from Iranian traditional sourdough on the technological and nutritional properties of whole wheat bread. Food Chem. 2020, 306, 125620. [CrossRef] [PubMed] 
16. Reale, A.; Di Renzo, T.; Succi, M.; Tremonte, P.; Coppola, R.; Sorrentino, E. Microbiological and fermentative properties of baker's yeast starter used in breadmaking. J. Food Sci. 2013, 78, M1224-M1231. [CrossRef]

17. Menteş, Ö.; Ercan, R.; Akçelik, M. Inhibitor activities of two Lactobacillus strains, isolated from sourdough, against rope-forming Bacillus strains. Food Control. 2007, 18, 359-363. [CrossRef]

18. Valerio, F.; De Bellis, P.; Di Biase, M.; Lonigro, S.L.; Giussani, B.; Visconti, A.; Lavermicocca, P.; Sisto, A. Diversity of spore-forming bacteria and identification of Bacillus amyloliquefaciens as a species frequently associated with the ropy spoilage of bread. Int. J. Food Microbiol. 2012, 156, 278-285. [CrossRef]

19. Garcia, M.V.; Bernardi, A.O.; Copetti, M.V. The fungal problem in bread production: Insights of causes, consequences, and control methods. Curr. Opin. Food Sci. 2019, 29, 1-6. [CrossRef]

20. Legan, J.D. Mould spoilage of bread: The problem and some solutions. Int. Biodeterior. Biodegrad. 1993, 32, 33-53. [CrossRef]

21. Bryden, W.L. Mycotoxins in the food chain: Human health implications. Asia Pac. J. Clin. Nutr. 2007, $16,95-101$.

22. Siragusa, S.; De Angelis, M.; Di Cagno, R.; Rizzello, C.G.; Coda, R.; Gobbetti, M. Synthesis of gamma-aminobutyric acid by lactic acid bacteria isolated from a variety of Italian cheeses. Appl. Environ. Microbiol. 2007, 73, 7283-7290. [CrossRef] [PubMed]

23. Wu, Q.; Tun, H.M.; Law, Y.S.; Khafipour, E.; Shah, N.P. Common distribution of gad operon in Lactobacillus brevis and its GadA contributes to efficient GABA synthesis toward cytosolic near-neutral pH. Front. Microbiol. 2017, 8, 206. [CrossRef] [PubMed]

24. Diana, M.; Quílez, J.; Rafecas, M. Gamma-aminobutyric acid as a bioactive compound in foods: A review. J. Funct. Foods 2014, 10, 407-420. [CrossRef]

25. Koubaa, M.; Delbecq, F.; Roohinejad, S.; Mallikarjunan, K. Gamma-Aminobutyric Acid. In Encyclopedia of Food Chemistry; Melton, L., Shahidi, F., Varelis, P., Eds.; Academic Press: Oxford, UK, 2019; pp. 528-534. [CrossRef]

26. Yilmaz, C.; Gokmen, V. Neuroactive compounds in foods: Occurrence, mechanism and potential health effects. Food Res. Int. 2020, 128, 108744. [CrossRef] [PubMed]

27. Venturi, M.; Galli, V.; Pini, N.; Guerrini, S.; Granchi, L. Use of selected lactobacilli to increase gamma-aminobutyric acid (GABA) content in sourdough bread enriched with amaranth flour. Foods 2019, 8. [CrossRef]

28. Bartkiene, E.; Bartkevics, V.; Mozuriene, E.; Lele, V.; Zadeike, D.; Juodeikiene, G. The safety, technological, nutritional, and sensory challenges associated with lacto-fermentation of meat and meat products by using pure lactic acid bacteria strains and plant-lactic acid bacteria bioproducts. Front. Microbiol. 2019, 10, 1036. [CrossRef]

29. Dimidi, E.; Cox, S.R.; Rossi, M.; Whelan, K. Fermented foods: Definitions and characteristics, impact on the gut microbiota and effects on gastrointestinal health and disease. Nutrients 2019, 11. [CrossRef]

30. Holzapfel, W.H.; Wood, B.J.B. Lactic Acid Bacteria: Biodiversity and Taxonomy; Wiley: Hoboken, NJ, USA, 2014.

31. Fraberger, V.; Unger, C.; Kummer, C.; Domig, K.J. Insights into microbial diversity of traditional Austrian sourdough. LWT Food Sci. Technol. 2020, 127. [CrossRef]

32. Call, L.-M.; D’Amico, S.; Grausgruber, H.; Schönlechner, R. Fruktane in alten und neuen österreichischen Weizensorten. Getreide Mehl Und Brot 2018, 2018, 2-6.

33. Magnusson, J.; Schnurer, J. Lactobacillus coryniformis subsp. coryniformis strain Si3 produces a broad-spectrum proteinaceous antifungal compound. Appl. Environ. Microbiol. 2001, 67, 1-5. [CrossRef]

34. Manini, F.; Casiraghi, M.C.; Poutanen, K.; Brasca, M.; Erba, D.; Plumed-Ferrer, C. Characterization of lactic acid bacteria isolated from wheat bran sourdough. LWT Food Sci. Technol. 2016, 66, 275-283. [CrossRef]

35. Stiles, J.; Penkar, S.; Plockova, M.; Chumchalova, J.; Bullerman, L.B. Antifungal activity of sodium acetate and Lactobacillus rhamnosus. J. Food Prot. 2002, 65, 1188-1191. [CrossRef]

36. Tremonte, P.; Pannella, G.; Succi, M.; Tipaldi, L.; Sturchio, M.; Coppola, R.; Luongo, D.; Sorrentino, E. Antimicrobial activity of Lactobacillus plantarum strains isolated from different environments: A preliminary study. Int. Food Res. J. 2017, 24, 852-859.

37. Demirbaş, F.; İspirli, H.; Kurnaz, A.A.; Yilmaz, M.T.; Dertli, E. Antimicrobial and functional properties of lactic acid bacteria isolated from sourdoughs. LWT Food Sci. Technol. 2017, 79, 361-366. [CrossRef] 
38. Svec, P.; Vancanneyt, M.; Seman, M.; Snauwaert, C.; Lefebvre, K.; Sedlacek, I.; Swings, J. Evaluation of $(\mathrm{GTG})_{5}$-PCR for identification of Enterococcus spp. FEMS Microbiol. Lett. 2005, 247, 59-63. [CrossRef] [PubMed]

39. Gevers, D.; Huys, G.; Swings, J. Applicability of rep-PCR fingerprinting for identification of Lactobacillus species. FEMS Microbiol. Lett. 2001, 205, 31-36. [CrossRef] [PubMed]

40. Watson, D.; O'Connell Motherway, M.; Schoterman, M.H.; van Neerven, R.J.; Nauta, A.; van Sinderen, D. Selective carbohydrate utilization by lactobacilli and bifidobacteria. J. Appl. Microbiol. 2013, 114, 1132-1146. [CrossRef]

41. Ehrmann, M.A.; Vogel, R.F. Molecular taxonomy and genetics of sourdough lactic acid bacteria. Trends Food Sci. Technol. 2005, 16, 31-42. [CrossRef]

42. Fraberger, V.; Call, L.M.; Domig, K.J.; D'Amico, S. Applicability of yeast fermentation to reduce fructans and other FODMAPs. Nutrients 2018, 10, 1247. [CrossRef]

43. Bryla, M.; Roszko, M.; Szymczyk, K.; Jedrzejczak, R.; Slowik, E.; Obiedzinski, M.W. Effect of baking on reduction of free and hidden fumonisins in gluten-free bread. J. Agric. Food Chem. 2014, 62, 10341-10347. [CrossRef]

44. Coda, R.; Cassone, A.; Rizzello, C.G.; Nionelli, L.; Cardinali, G.; Gobbetti, M. Antifungal activity of Wickerhamomyces anomalus and Lactobacillus plantarum during sourdough fermentation: Identification of novel compounds and long-term effect during storage of wheat bread. Appl. Environ. Microbiol. 2011, 77, 3484-3492. [CrossRef] [PubMed]

45. Gerez, C.L.; Torino, M.I.; Rollán, G.; Font de Valdez, G. Prevention of bread mould spoilage by using lactic acid bacteria with antifungal properties. Food Control. 2009, 20, 144-148. [CrossRef]

46. Axel, C.; Brosnan, B.; Zannini, E.; Peyer, L.C.; Furey, A.; Coffey, A.; Arendt, E.K. Antifungal activities of three different Lactobacillus species and their production of antifungal carboxylic acids in wheat sourdough. Appl. Microbiol. Biotechnol. 2016, 100, 1701-1711. [CrossRef]

47. Belz, M.C.; Mairinger, R.; Zannini, E.; Ryan, L.A.; Cashman, K.D.; Arendt, E.K. The effect of sourdough and calcium propionate on the microbial shelf-life of salt reduced bread. Appl Microbiol. Biotechnol. 2012, 96, 493-501. [CrossRef] [PubMed]

48. Schwenninger, S.M.; von Ah, U.; Niederer, B.; Teuber, M.; Meile, L. Detection of antifungal properties in Lactobacillus paracasei subsp. paracasei SM20, SM29, and SM63 and molecular typing of the strains. J. Food Prot. 2005, 68, 111-119. [CrossRef]

49. Magnusson, J.; Ström, K.; Roos, S.; Sjögren, J.r.; Schnürer, J. Broad and complex antifungal activity among environmental isolates of lactic acid bacteria. FEMS Microbiol. Lett. 2003, 219, 129-135. [CrossRef]

50. Lavermicocca, P.; Valerio, F.; Evidente, A.; Lazzaroni, S.; Corsetti, A.; Gobbetti, M. Purification and characterization of novel antifungal compounds from the sourdough Lactobacillus plantarum strain 21B. Appl. Environ. Microbiol. 2000, 66, 4084-4090. [CrossRef]

51. Muhialdin, B.J.; Algboory, H.L.; Kadum, H.; Mohammed, N.K.; Saari, N.; Hassan, Z.; Meor Hussin, A.S. Antifungal activity determination for the peptides generated by Lactobacillus plantarum TE10 against Aspergillus flavus in maize seeds. Food Control. 2020, 109. [CrossRef]

52. Russo, P.; Arena, M.P.; Fiocco, D.; Capozzi, V.; Drider, D.; Spano, G. Lactobacillus plantarum with broad antifungal activity: A promising approach to increase safety and shelf-life of cereal-based products. Int. J. Food Microbiol. 2017, 247, 48-54. [CrossRef]

53. Bartkiene, E.; Zavistanaviciute, P.; Lele, V.; Ruzauskas, M.; Bartkevics, V.; Bernatoniene, J.; Gallo, P.; Tenore, G.C.; Santini, A. Lactobacillus plantarum LUHS135 and paracasei LUHS244 as functional starter cultures for the food fermentation industry: Characterisation, mycotoxin-reducing properties, optimisation of biomass growth and sustainable encapsulation by using dairy by-products. LWT Food Sci. Technol. 2018, 93, 649-658. [CrossRef]

54. Hassan, Y.I.; Bullerman, L.B. Antifungal activity of Lactobacillus paracasei subsp. tolerans against Fusarium proliferatum and Fusarium graminearum in a liquid culture setting. J. Food Prot. 2008, 71, 2213-2216. [CrossRef]

55. Gajbhiye, M.; Kapadnis, B. Bio-efficiency of antifungal lactic acid bacterial isolates for pomegranate fruit rot management. Proc. Natl. Acad. Sci. India Sect. B Biol. Sci. 2017, 88, 1477-1488. [CrossRef]

56. Schnürer, J.; Magnusson, J. Antifungal lactic acid bacteria as biopreservatives. Trends Food Sci. Technol. 2005, 16, 70-78. [CrossRef] 
57. Pepe, O.; Blaiotta, G.; Moschetti, G.; Greco, T.; Villani, F. Rope-producing strains of Bacillus spp. from wheat bread and strategy for their control by lactic acid bacteria. Appl. Environ. Microbiol. 2003, 69, 2321-2329. [CrossRef]

58. Arena, M.P.; Silvain, A.; Normanno, G.; Grieco, F.; Drider, D.; Spano, G.; Fiocco, D. Use of Lactobacillus plantarum Strains as a Bio-Control Strategy against Food-Borne Pathogenic Microorganisms. Front. Microbiol. 2016, 7, 464. [CrossRef]

59. Mantzourani, I.; Plessas, S.; Odatzidou, M.; Alexopoulos, A.; Galanis, A.; Bezirtzoglou, E.; Bekatorou, A. Effect of a novel Lactobacillus paracasei starter on sourdough bread quality. Food Chem. 2019, 271, 259-265. [CrossRef]

60. Digaitiene, A.; Hansen, A.S.; Juodeikiene, G.; Eidukonyte, D.; Josephsen, J. Lactic acid bacteria isolated from rye sourdoughs produce bacteriocin-like inhibitory substances active against Bacillus subtilis and fungi. J. Appl. Microbiol. 2012, 112, 732-742. [CrossRef]

61. Villegas, J.M.; Brown, L.; de Giori, G.S.; Hebert, E.M. Optimization of batch culture conditions for GABA production by Lactobacillus brevis CRL 1942, isolated from quinoa sourdough. LWT Food Sci. Technol. 2016, 67, 22-26. [CrossRef]

Publisher's Note: MDPI stays neutral with regard to jurisdictional claims in published maps and institutional affiliations.

(C) 2020 by the authors. Licensee MDPI, Basel, Switzerland. This article is an open access article distributed under the terms and conditions of the Creative Commons Attribution (CC BY) license (http://creativecommons.org/licenses/by/4.0/). 